\title{
Editorial
}

\section{Gestational Diabetes Mellitus: A Rising Threat to Public Health}

\author{
Fatema Ashraf ${ }^{1}$, M. Tasdik Hasan ${ }^{2}$
}

GDM is a rising threat to public health (Chen et al., 2012). It has accounted 20.9 million births globally in 2015 (Zhu and Zhang 2016) while in Bangladesh the prevalence is 12.9\% (Mahtab and Bhowmik 2016). In neglected cases GDM leads to maternal and foetal morbidities and mortalities which is alarming in underprivileged society. The maternal morbidities are in the form of prolonged labour, obstructed labour, increased rate of caesarean section and maternal infections which may develop following type 2 diabetes mellitus subsequently (Jesmin et al., 2014). On the other hand baby's may suffer from macrosomia, foetal distress, birth injuries, birth asphyxia, neonatal hypoglycemia, neonatal death and development of type 2 diabetes mellitus in early adult life (Buchanan et al., 2012).

Throughout day and night, keeping blood sugar level within normal is the main stay of GDM management (American Diabetes Association 2010). However in any form, the management includes measured diet, life style modification, drugs and on the top maintains discipline. Therefore, diabetes management model during pregnancy should involve the victim in its every steps of management to make it a successful one.

'Patient empowerment' is thought to play a pivotal role to manage diabetes during pregnancy (Chen et al., 2012). For empowerment the patient should have a clear understanding about the disease, its pathogenesis and short and long term consequences over both the mother and the baby. Furthermore, the patient can assess and interpret her own blood sugar. Simple health education in one sitting may not work worthy, rather continuous learning, training and monitoring of patients performances through successive sessions can give a better outcome. Thus a patient empowerment model was developed and applied to find out its efficacy for GDM management at a selected Tertiary level Public hospital where intervention was done (Niromanesh et al., 2012). A control group was recruited from similar tertiary level public hospital. Result showed lower rate of maternal infections, higher rate of vaginal birth (66.7\%vs33.3\%) and low use of Inj. Insulin (25\% vs $75 \%)$ in intervention group in comparison to control group.

Continuous patient's training on diet calculation and diet exchange are essential which is based on daily calorie requirement and blood sugar level interpretation (Cheng et al., 2012). This is followed by redistribution of diet in appropriate meal which is matched with food supply. This is the core of dietary management and therefore, each patient needs to be admitted for at least 3 to 4 days (Luoto et al., 2011). It seems quite impractical for large scale study to admit the patient for health education and to empower them at the end. In this context, the scientist clinician group thought to overcome the challenge by applying apps. Group of ICT people are working on this issue and are using the artificial intelligence (AI) based software which may be an effective tool for management of GDM cases (Magon and Seshiah 2011). If it is a successful one a great success in the management of GDM will be achieved in this century.

[Journal of Science Foundation 2016;14(2):34-35]

\section{References}

American Diabetes Association. Diagnosis and classification of diabetes mellitus. Diabetes care. 2010;33(Supplement 1):S62-9 Buchanan TA, Xiang AH, Page KA. Gestational diabetes mellitus: risks and management during and after pregnancy. Nature Reviews Endocrinology. 2012;8(11):639-49.

\footnotetext{
${ }^{1}$ Professor \& Head, Department of Obstetrics \& Gynecology, Shaheed Suhrawardy Medical College, Dhaka, Bangladesh ${ }^{2}$ Research Investigator, International Center for Diarrhoeal Diseases Research, Dhaka, Bangladesh
}

Correspondence: Prof. Dr. Fatema Ashraf, Professor \& Head, Department of Obstetrics \& Gynecology, Shaheed Suhrawardy Medical College, Sher-E-Bangla Nagar, College Gate, Dhaka-1207, Bangladesh; Email: fatema.phfbd@ gmail.com; Cell no: $+8801711855941$ 
Chen L, Magliano DJ, Zimmet PZ. The worldwide epidemiology of type 2 diabetes mellitus - present and future perspectives. Nature Reviews Endocrinology. 2012;8(4):228-36

Cheng YW, Chung JH, Block-Kurbisch I, Inturrisi M, Caughey AB. Treatment of gestational diabetes mellitus: glyburide compared to subcutaneous insulin therapy and associated perinatal outcomes. The Journal of Maternal-Fetal \& Neonatal Medicine. 2012;25(4):379-84.

Jesmin S, Akter S, Akashi H, Al-Mamun A, Rahman MA, Islam MM, et al. Screening for gestational diabetes mellitus and its prevalence in Bangladesh. Diabetes research and clinical practice. 2014;103(1):57-62.

Luoto R, Kinnunen TI, Aittasalo M, Kolu P, Raitanen J, Ojala K, et al. Primary prevention of gestational diabetes mellitus and largefor-gestational-age newborns by lifestyle counseling: a cluster-randomized controlled trial. PLoS Med 2011;8(5):e1001036.

Magon N, Seshiah V. Gestational diabetes mellitus: Non-insulin management. Indian journal of endocrinology and metabolism. 2011;15(4):284.

Mahtab H, Bhowmik B. Gestational Diabetes Mellitus-Global and Bangladesh Perspectives. J Endocrinol 2016;3(2):1041

Niromanesh S, Alavi A, Sharbaf FR, Amjadi N, Moosavi S, Akbari S. Metformin compared with insulin in the management of gestational diabetes mellitus: a randomized clinical trial. Diabetes research and clinical practice. 2012;98(3):422-9.

Poomalar GK. Changing trends in management of gestational diabetes mellitus. World journal of diabetes. 2015;6(2):284

Zhu Y, Zhang C. Prevalence of gestational diabetes and risk of progression to type 2 diabetes: a global perspective. Current Diabetes Reports 2016;16(1):7 